
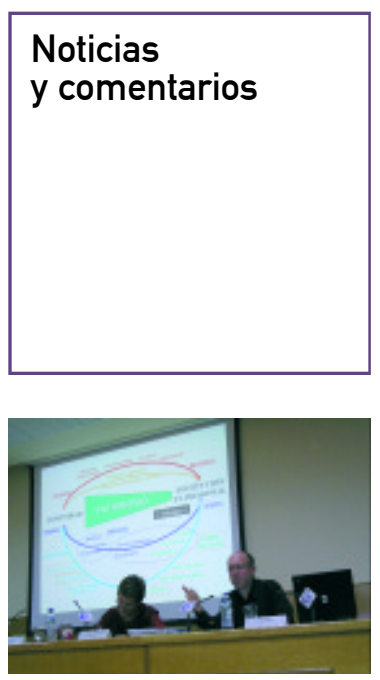

Lluis Bonet, (Universidad de Barcelona) y María de los Ängeles Querol (Universidad Complutense de Madrid)

\title{
El sector privado incrementa las oportunidades de trabajar en patrimonio
}

Los pasados 28 y 29 de noviembre de 2005, la Fundación de Casas Históricas y Singulares, en colaboración con la Facultad de Geografía e Historia de la Universidad Complutense de Madrid y el Instituto Superior del Arte, y con el apoyo económico del Ministerio de Cultura, celebró las Jornadas sobre salidas profesionales relacionadas con el Patrimonio Cultural. Los objetivos fundamentales que la Fundación se había marcado al plantear este foro fueron dos: la implicación de las generaciones más jóvenes en las tareas de conservación del Patrimonio Histórico, a través de la exposición de las distintas salidas profesionales que pueden elegir tras la realización de sus estudios, y la localización de los denominados nichos de actividad en esta materia debido a que en la actualidad se están demandando expertos que no son fáciles de encontrar en el ámbito profesional.

De entre todas las cuestiones que se suscitaron en las jornadas, tal vez sean cuatro de ellas las que presentaron mayor interés:

$>$ En primer lugar, se puso de manifiesto que pese a la tradicional importancia del sector público (universidad, administraciones, centros de investigación) para asumir profesionales ligados al Patrimonio Histórico, en la actualidad el sector privado ofrece las mismas e incluso mejores perspectivas. En la conferencia dedicada al voluntariado cultural, el ponente incidió en la idea de la participación del sector privado (empresarial, ciudadanía y voluntariado) en el ámbito de la cultura. Asimismo, María de los Ángeles Querol, directora académica de las jornadas, ofreció el dato de que el noventa por ciento de los ingresos de las empresas de arqueología proviene del sector privado, y sólo el diez por ciento del público, y el catedrático de Historia del Arte Miguel Ángel Castillo aludió a la búsqueda de nichos de actividad por parte de los historiadores del arte para salir del ámbito estrictamente académico y por entender el Patrimonio Cultural como un objeto de estudio global.

$>$ En segundo lugar, se hizo especial hincapié en la necesidad de abordar las actividades e intervenciones sobre el Patrimonio Histórico desde un enfoque multidisciplinar.

De igual forma, al tratar el voluntariado cultural se puso de relieve que el voluntariado no es una actuación individual, sino que hay que ligarlo al ámbito de una organización, siendo ése uno de los rasgos (junto al altruismo y a la continuidad) que precisamente lo define.
$>$ Por otro lado, se constató que las profesiones ligadas al Patrimonio Cultural han sufrido y sufren un mal poco extendido en otros ámbitos: el intrusismo. La sociedad parece no haber asumido que las intervenciones en bienes pertenecientes al Patrimonio Cultural han de realizarlas profesionales. Esta situación tiene probablemente un doble origen: por un lado, la falta de formación académica o la instauración reciente de asignaturas en materia de bienes culturales, aún en estudios directamente relacionados con el Patrimonio Histórico; y por otro, la falta de regulación normativa de estas profesiones.

> Por último, se abordó la poco analizada cuestión del voluntariado cultural. Resulta evidente que el voluntariado cultural no es una salida profesional, pero era un tema que desde la Fundación de Casas Históricas y Singulares se quería tratar porque sus límites y los del mercado laboral se han presentado en ocasiones como difusos y porque en algunos momentos no se ha sabido encajar satisfactoriamente la presencia de voluntarios y personal en algunas instituciones, tanto privadas como públicas.

Para finalizar, tampoco puede dejarse de hacer referencia a una cuestión que estuvo presente a lo largo de las jornadas, por más que sea un tema general y que afecta a ámbitos que exceden el de las salidas profesionales estrictamente: me refiero, en concreto, a la visión del Patrimonio Cultural no sólo como un conjunto de elementos (materiales e inmateriales) que conforman la memoria histórica de un pueblo, sino también como un recurso económico que facilita el desarrollo de numerosos territorios y la creación de empleos no sólo directos sino también indirectos (transporte, seguridad, etc.). Así, poco a poco se va cambiando la imagen de que los recursos dedicados a la conservación, restauración y difusión de los bienes históricos son un gasto y se afianza la idea de considerarlos como una inversión.
Ana Yáñez

Gerente de la Fundación de Casas Históricas y Singulares 